\title{
EFEITOS DO BENTAZON SOBRE A PRODUÇÃO E TEORES DE N E ÓLEO EM SOJA (GLYCINE MAX (L.) MERRILL.)
}

\section{RESUMO}

Os efeitos do bentazon sobre a produção e sobre o teor de $\mathrm{N}$ e de óleo total nos grãos em soja das variedades Paraná, IAC-4, Santa Rosa e UFV-1 foram estudados em um experimento de campo. O bentazon foi aplicado na dose de 1,44 $\mathrm{kg} / \mathrm{ha}$ sobre plantas com um, dois ou três trifólios totalmente desenvolvidos.

Não foram encontradas diferenças entre as produções, teores de $\mathrm{N}$ ou de óleo em qualquer das variedades estudadas. A Paraná e a IAC-4 produziram mais que as outras duas. O teor de $\mathrm{N}$ foi significativamente mais baixo na Santa Rosa e o de óleo, significativamente mais elevado na Paraná e mais baixo na UFV-1.

PALAVRAS CHAVES: Glycine max (L.) Merrill, bentazon, teor de N, teor de óleo, produção.

\section{SUMMARY}

EFFECTS OF BENTAZON ON YIELD AND

N AND OIL CONTENT IN SOYBEAN

The effects of bentazon on yield and on $\mathrm{N}$ and oil content in grains, applied at $1,44 \mathrm{~kg} / \mathrm{ha}$, at three, growth stages, on soybeans, cv. Paraná, IAC-4, Santa Rosa and. UFV-1, were studied in a field experiment.

No differences were found for yields or $\mathrm{N}$ and oil contents in any of the cultivars for application dates. Paraná and IAC-4 yielded more than the other two. N content was significantly lower in Santa Rosa and oil content significantly higher in Paraná and lower in UFV-1.

KEYWORDS: Glycine max L. Merril, bentazon, $\mathrm{N}$ content, oil content.

\author{
R. DEUBER \\ Pesquisador Cientifico \\ Seção de Fisiologia - Instituto Agronómico. Caixa \\ Postal 28 - 13.100, Campinas - SP.
}

\section{INTRODUÇÃO}

O grande crescimento da cultura da soja no Brasil foi acompanhado por um aumento constante do uso de herbicidas. No início foram utilizados, principalmente, aqueles incorporados ao solo, passando-se a um uso crescente de herbicidas de préemergência. De modo geral, esses herbicidas se caracterizam por um controle mais eficiente de gramineas, ficando o de dicotiledôneas aquém do ideal.

Devido a esse fato, surgiram, mais recentemente, herbicidas de pós-emergência, seletivos à cultura da soja, e eficientes no controle de dicotiledôneas. Esses produtos têm sido usados como tratamento complementar ao uso de um graminicida. Entre os herbicidas de pós-emergência, está incluído o bentazon, já de uso bem difundido atualmente (2).

Por ser de aplicação em área total, o bentazon pode, em algumas ocasiões, causar efeitos fitotóxicos à soja, como clorose e necrose em partes das folhas. Em um trabalho com esse herbicida, em que foi obtida a produção de grãos, não se verificaram diferenças entre oito 
variedades (1), ao passo que outros autores encontraram um grupo de genótipos altamente sensiveis ao bentazon (6).

Não foram encontrados trabalhos que estudem a possivel interferência do bentazon na qualidade dos grãos produzidos, sendo o objetivo deste verificar a sua influência sobre os teores de $\mathrm{N}$ e de óleo total, quando aplicado em diferentes épocas sobre quatro variedades de soja.

\section{MATERIAIS E MÉTODOS}

O experimento foi instalado em um latossolo vermelho-escuro, série Barão (4). A análise química revelou as seguintes características: $3,6 \%$ de matéria orgânica, pH de 5,5, e os valores de e.mg/ $100 \mathrm{ml}$ de TFSA de 0,0 para $\mathrm{Al}^{+++}$de 4,4 para $\mathrm{Ca}^{++}$e de 0,6 para $\mathrm{Mg}^{++}$, e os valores, de $\mu \mathrm{g} / \mathrm{ml}$ de TFSA de 256 para $\mathrm{K}$ e de 87 para $\mathrm{P}$. A análise física revelou os seguintes valores: $38,0 \%$ de argila, 4,4\% de limo, 15,6\% de areia fina e 42,0\% de areia grossa, sendo o solo da classe textural barrenta.

As variedades de soja utilizadas foram IA C-4, UFV-1, Santa Rosa e Para ná.

A semeadura foi realizada, manualmente, no dia $1 .^{\circ}$ de dezembro de 1978 , sem inoculação, deixando-se após a emergência, 15 plantas por metro linear. Cada parcela media $2,40 \mathrm{~m}$ de largura por $10,0 \mathrm{~m}$ de comprimento, subdividida em quatro subparcelas de 1,20m x 5,OOm, com duas linhas espaçadas de $0,60 \mathrm{~m}$. O delineamento foi o de blocos ao acaso, com quatro repetições. Cada subparcela foi semeada com uma variedade diferente.

Os tratamentos consistiam de aplicação de bentazon [3-isopropil-2,1,3benzotio diazin on a-(4) -2, 2-dioxid o], a $1,44 \mathrm{~kg} /$ ha do i.a., em formulação contendo $480 \mathrm{~g} / 1\left(^{*}\right)$ aos 22,29 ou 35 dias após a semeadura e um tratamento sem aplicação. As plantas se apresentavam, respectivamente, com o $1 .^{\circ}$ trifólio, o $2 .^{\circ}$ trifólio e o $3 .^{\circ}$ trifólio totalmente desenvolvidos, para as diferentes épocas de

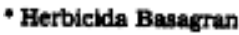

aplicação. Esta foi realizada em área total sobre a cultura. Utilizou-se um pulverizador impulsionado a gás carbônico, com barra de cinco bicos 8002, com gasto de calda equivalente a 450 1/ha. Todas as parcel as foram capinadas, quando necessário, para eliminação de plantas daninhas que não foram controladas pelos herbicidas, assim co mo as testemunhas.

A cultura foi observada visualmen te após as aplicações. A colheita da variedade Paraná se fez em 14 de maio de 1979 e das demais em 22 de maio, com as plantas totalmente sem folhas e todas as vagens secas.

Foi obtido o peso de grãos secos ao ar, para cada tratamento. Retirou-se uma amostra de $100 \mathrm{~g}$ de grãos de cada subparcela que após secagem a $70^{\circ} \mathrm{C}$, foi moída e parte submetida à análise do teor de $\mathrm{N}$ total e óleo total. $\mathrm{O} \mathrm{N}$ foi analisado imediatamente após a colheita e o óleo, sete meses após. O N foi determinado por destilação com microKjeldahl e o teor de óleo total por ex tração a quente com hexano em Soxh let.

\section{RESULTADOS E DISCUSSÃO}

A produção de grãos e os teores de $\mathrm{N}$ e de óleo total nos grãos, na colheita, estão indicados no Quadro 1.

Após a aplicação do bentazon sobre plantas com o primeiro trifólio, verifi cou-se clorose generalizada, manchas necróticas nas folhas e retenção de crescimento em todas as variedades. Nas aplicações nos dois estádios seguintes, ocorreu também clorose generalizada, porém, mais leve, sendo as manchas necróticas nas folhas em menor grau.

Dentro de variedades somente ocorreu diferença significativa, para a produção de grãos, na Santa Rosa. O tratamento aplicado quando a soja se apresentava com apenas o $1 .^{\circ}$ trifólio foi o que apresentou menor produção, diferindo daquele que recebeu o herbicida no estádio de $2 .^{\circ}$ trifólio completamente desenvolvido. Esse resultado leva a crer que a variedade Santa Rosa foi mais sensivel à aplicação do bentazon no 


\begin{tabular}{|c|c|c|c|c|c|c|c|c|c|c|c|c|c|c|c|}
\hline \multirow{2}{*}{$\begin{array}{l}\text { EPOCAS DE } \\
\text { APUCAÇÃ̄0 }\end{array}$} & \multicolumn{3}{|c|}{ PARANÁ } & \multicolumn{3}{|c|}{ SANTA ROSA } & \multicolumn{3}{|c|}{ IAC - 4} & \multicolumn{3}{|c|}{ UFV - 1} & \multicolumn{3}{|c|}{ MÉDIAS } \\
\hline & grióos & $\mathbf{N}$ & óleo & grãos & $\mathbf{N}$ & óleo & grẫos & $\mathbf{N}$ & óleo & grios & $\mathbf{N}$ & óleo & grãos & $\mathbf{N}$ & óleo \\
\hline & $\mathrm{kg} / \mathrm{ha}$ & $\%$ & $\%$ & $\mathrm{~kg} / \mathrm{ha}$ & $\%$ & $\%$ & $\mathrm{~kg} / \mathrm{ha}$ & $\%$ & $\%$ & kg/ha & $\%$ & $\%$ & $\mathrm{~kg} / \mathrm{ha}$ & $\%$ & $\%$ \\
\hline $10^{0}$ trifólio & 2.567 & 7,06 & 22,64 & $1.787 \mathrm{~b}$ & 6,92 & 20,60 & 2.492 & 7,15 & 20,18 & 1.971 & 7,42 & 20,00 & 2.204 & 7,14 & 20,85 \\
\hline $2 .^{\circ}$ trifólio & 2.650 & 7,28 & 21,95 & $2.454 \mathrm{a}$ & 6,06 & 21,97 & 2.496 & 7,13 & 20,27 & 2.033 & 6,97 & 19,83 & 2.408 & 6,86 & 21,01 \\
\hline $3 .^{\circ}$ trifólio & 2.262 & 7,01 & 22,12 & $1.987 \mathrm{ab}$ & 6,27 & 20,85 & 2.608 & 7,74 & 20,06 & 2.012 & 7,56 & 20.71 & 2.218 & 7,14 & 20,89 \\
\hline Sem aplicaçāo & 2.362 & 7,24 & 22,55 & $2.171 \mathrm{ab}$ & 6,86 & 20,96 & 2.596 & 7,26 & 20,45 & 2.283 & 7,10 & 19,90 & 2.353 & 7,11 & 20,97 \\
\hline F (grãos) $11,19^{*} \cdot$ & $2.460 \mathrm{a}$ & & & $2.100 \mathrm{~b}$ & & & $2.548 \mathrm{a}$ & & & $2.075 \mathrm{~b}$ & & & n.s. & & \\
\hline $\mathrm{F}(\mathrm{N}) \quad 10,43^{*} \cdot$ & & $7,15 \mathrm{a}$ & & & $6,53 \mathrm{~b}$ & & & $7,32 \mathrm{a}$ & & & $7,26 \mathrm{a}$ & & & n.s. & \\
\hline F (óleo) $15,39 * *$ & & & $22,32 a$ & & & $21,09 \mathrm{~b}$ & & & $20,24 b c$ & & & $20,06 \mathrm{c}$ & & & n.s. \\
\hline
\end{tabular}

(**) Valores significativos do teste $F$, ao nível de $1 \%$.

Valores de médias, nas linhas, sob o quadro, seguidos de mesma letra, nào diferem, entre si, ao nível de $5 \%$ pelo teste de Tukey.

Apenas ocorreu diferença significativa, dentro de variedades, para valores de produção de grãos, da Santa Rosa. 
estádio de $1 .^{\circ}$ trifólio. No entanto, nenhum dos dois tratamentos diferiu da testemunha. Para o conjunto das quatro variedades, não foi verificada diferença entre épocas de aplicação, quanto à produção de grãos. As variedades IAC-4 e Paraná, em média dos tratamentos, apresentaram produções significativamente maiores do que as outras duas. Esses resultados concordam com aqueles encontrados por Miranda et al. (5) em diferentes experimentos de campo.

Os teores de $\mathrm{N}$ não apresentaram quaisquer diferenças, dentro de variedades, ou no geral, para as épocas de aplicação do bentazon. Ocorreu diferença apenas no teor de $\mathrm{N}$ entre variedades, tendo a Santa Rosa apresentado o menor valor das quatro. Esse resultado não concorda com aquele encontrado por Bataglia et al. (3), em que a variedade Paraná continha o menor teor de $\mathrm{N}$ entre nove variedades. A discrepância poderia ser explicada por diferenças edáficas entre os experimentos.

Para os teores de óleo, também não foram verificadas quaisquer diferenças entre tratamentos, quer dentro de variedades, quer no conjunto das quatro. Entre variedades, houve diferenças significativas apresentando, a
Paraná, o valor mais elevado e a UFV-1, o menor valor. Os resultados encontrados são concordantes com os valores médios apresentados para cada variedade por Miranda et al. (5).

Os parâmetros estudados levam à conclusão que as quatro variedades são tolerantes ao bentazon, não possuindo nenhuma delas sensibilidade, como encontrado por Wax et al. (6) para alguns genótipos, em seu trabalho.

\section{LITERATURA CITADA}

1. Andersen, R.N.; Lueschen, W.E.; Warnes, D.D. \& Nelson, W.W.. Controlling broadlef weeds in soybean with bentazon in Minnesota. Weed Sci. 22:136-142, 1974.

2. BASF Brasileira S.A. Basagran - nunca houve um herbicida igual a este. Mimeo. S. data. $31 p$.

3. Bataglia, O.C.; Mascarenhas, H.A.A. \& Tisselli F.o, O., Composiçáo mineral das sementes de nove cultivares de soja. Bracantia $36: X L V I I-L, 1977$, (nota 12).

4. Melin, A.J.; Girardi, V.A.V. \& Moniz, A.C., Mineralogia dos solos da Estaçáo Experimental "Theodureto de Camargo", em Campinas. Bragantia 25:9-30, 1966.

5. Miranda, M.A.C.; Miyasaka, s.; Mascarenhas, H.A.A. \& Rosseto, D., Melhoramento da soja no Estado de Báo Paulo. In: A soja no Brasil Central. Fundaçáo Cargill, p.25-53, 1977.

6. Wax, L.M.; Bernard, R.L. \& Hayes, R.M., Responses of soybean cultivars to bentazon bromoxynil, chloroxuron and 2,4-DB. Weed Sci. 22:35-41, 1974. 